\title{
Prinsip Kepemimpinan Character of A Leader pada Era Generasi Milenial
}

\author{
Amiroh Ambarwati 1, Susilo Teguh Raharjo ${ }^{2}$ \\ ${ }^{1}$ Balai Diklat Keagamaan Semarang, ${ }^{2}$ Akademi Kepolisian \\ 1amirohambarwati@ymail.com
}

\begin{abstract}
Abstrak. Tujuan dari penulisan karya ilmiah ini adalah mengetahui prinsip kepemimpinan Character of $\boldsymbol{A}$ Leader yang sesuai untuk generasi milenial. Generasi millenial dewasa ini tidak hanya unggul dalam bidang teknologi dan ilmu pengetahuan, kaum muda ini kini mulai menjadi trendsetter dalam bidang social, politik, budaya dan ekonomi. Di era globalisasi, tidak bisa dipungkiri bahwa seiring berkembangnya teknologi yang berbasis digital application, para generasi millennial rentan akan dampak negatif yang ditimbulkan oleh media sosial, namun di lain sisi, generasi muda ini juga memberikan pengaruh yang signifikan terhadap kemajuan bangsa sehingga dibutuhkan karakter pemimpin yang sesuai untuk memimpin generasi milenial. Metode yang digunakan dalama penulisan karya ilmiah yaitu studi literatur melalui buku, jurnal, dan berita cetak/online. Karya ilmiah ini memberikan gambaran bagaimana karakter pemimpin yang cocok untuk generasi milenial. Berdasarkan studi literature karakter yang harus dimiliki pemimpin milenal 1) Mampu menjadi teladan yang baik, 2) Memiliki rasa tanggung jawab 3) Berani mengambil dan bersedia menerima resiko 4) Mempunyai sense of belonging dari para bawahan dan sense of participation 5) Menciptakan kerjasama yang baik di kalangan anggota merupakan karakter
\end{abstract}

Kata Kunci : Kepemimpinan, Character, Generasi Milenial

\section{Pendahuluan}

Generasi Y (generasi millennial) adalah generasi yang lahir pada era 80-90an. Banyak istilah popular tentang generasi ini; connected or digital generation atau gen why yang identik dengan karakter berani, inovatif, kreatif, dan modern (Erkutlu, 2011). Generasi millennial merupakan generasi modern yang aktif bekerja, penelitian, dan berpikir inovatif tentang organisasi, memiliki rasa optimisme dan kemauan untuk bekerja dengan kompetitif, terbuka, dan fleksibel. Di lain sisi, generasi Baby Boomers/generasi X (generasi yang lahir pada era 6589an) dibesarkan di dalam suatu organisasi dengan struktur organisasi yang hierarkhis dan struktur manajemen yang datar sehingga sistem kerjasama yang timbul di dalam organisasi didasarkan pada tuntutan pekerjaan (teamwork-based job roles) (Egbert \& Pérez-Mercader, 2016).

Berbeda dengan generasi Baby Boomers, generasi millennial mempunyai harapan yang sangat berbeda tentang permasalahan ekonomi, lingkungan, hingga persoalan sosial politik. Secara merata generasi millennial mempunyai pendidikan yang lebih baik dari para Baby 
Philanthropy Journal of Psychology

Vol 2 Nomor 2 (2018), 114-127

ISSN 2580-6076 (Print), ISSN 2580-8532 (Online)

Boomers, mereka cukup terbiasa dengan teknologi bahkan sebagian besar dari mereka sangat ahli dengan teknologi. Dengan kepercayaan diri yang tinggi, generasi millennial mampu bekerja kreatif dan selalu mempunyai energi positif di berbagai bidang (Cullen et al., 1999)

Meningkatnya jumlah millennial (Generasi Y) yang masuk ke dalam dunia kerja dengan keistimewaan yang cenderung berbeda dengan generasi - generasi sebelumnya menjadi salah satu tantangan baru bagi dunia kerja. Millennial sering disebut - sebut sebagai generasi yang menyukai kebebasan dan fleksibilitas seperti kebebasan bekerja, belajar maupun berbisnis. Generasi Millenial, yang juga punya nama lain Generasi Y, adalah kelompok manusia yang lahir di atas tahun 1980-an hingga 1997. Mereka disebut millennial karena satu - satunya generasi yang pernah melewati millennium kedua sejak teori generasi ini dihembuskan pertama kali oleh Karl Mannheim pada 1923 (Koçak \& Burgaz, 2017).

Saat ini, lapangan pekerjaan di Indonesia didominasi oleh generasi X dan Y. Dari data karir.com tahun 2015 (dalam swa.co.id, 2015) menunjukkan bahwa Gen X yang memiliki gelar S1 sebanyak 64\% dan tersebar dalam proporsi jabatan sebagai Department Manager (23\%), Senior Staff (18\%) dan Supervisor (17\%). Sedangkan generasi Y, 62\% di antaranya mengantongi gelar S1, dan meski 51\% di antara total jumlah pengguna fitur karir.com masih berada pada entry level, dimana untuk posisi Senior Staff mencapai 22\% dan pada tingkat Supervisor 13\%. Dari data tersebut dapat dilihat bahwa pertumbuhan karir generasi Y lebih progresif dibandingkan dengan generasi X (Somech, Anit: Drach-Zahavy, 2004).

Di era globalisasi ini, semakin banyak tantangan dalam setiap sisi. Baik dalam dunia kerja, kehidupan sehari - hari ataupun dunia pendidikan. Keberadaan seorang pemimpin dalam organisasi ataupun individu sangat dibutuhkan untuk membawa organisasi atau individu kepada tujuan yang telah ditetapkan. Berbagai gaya kepemimpinan akan mewarnai perilaku seorang pemimpin dalam menjalankan tugasnya. Karakteristik generasi Y mendorong tren dimana anak muda sekarang lebih selektif dalam memilih pekerjaan yang sesuai, dan hal ini tidak lepas dari sikap kepemimpinan yang mereka miliki. Tahun 2020 hingga tahun 2030 diprediksi bahwa Indonesia akan mencapai puncak populasi usia produktif sebesar 70\% dari total penduduk Indonesia (Sebastian, Amran dan Youth Lab, 2016). Hal ini bisa menjadi keuntungan untuk perekonomian dan kemajuan Indonesia apabila generasi millenial sebagai generasi dengan jumlah yang besar dapat dikelola dengan baik sehingga dibutuhkan karakter pemimpin yang cocok untuk generasi milenial (Bosscher, 2013). 
Philanthropy Journal of Psychology

Vol 2 Nomor 2 (2018), 114-127

ISSN 2580-6076 (Print), ISSN 2580-8532 (Online)

Berdasarkan fenomena tersebut penulis tertarik untuk membuat suatu analisis terkait karakter pemimpin untuk generasi milenial. Berdasarkan studi literature karakter yang harus dimiliki pemimpin milenal 1) Mampu menjadi teladan yang baik, 2) Memiliki rasa tanggung jawab 3) Berani mengambil dan bersedia menerima resiko 4) Mempunyai sense of belonging dari para bawahan dan sense of participation 5) Menciptakan kerjasama yang baik di kalangan anggota merupakan karakter yang harus dimiliki oleh pemimpin di generasi milenial (Brander, Patterson, \& Chan, 2012).

\section{Metode}

Metode yang digunakan yaitu studi literatur melalui buku, jurnal, dan berita online. Karya ilmiah ini memberikan gambaran terkait prinsip kepemimpinan character of a leader pada era generasi milenial. Serta memberikan gambaran terkait peran pemimpin era milienal sebagai generasi penerus bangsa untuk mampu bertanggungjawab mempersiapkan masa depan dengan berperilaku positif untuk menciptkan generasi emas.

\section{Hasil dan Diskusi}

Definisi generasi menurut Kupperschmidt adalah suatu identitas kelompok dengan tahun kelahiran, masa (era) dan peristiwa bersejarah yang sama sebagai tahap kritis perkembangannya (Dries, Pepermans, De Kerpel, 2008). Empat generasi yakni Tradisionalis, Baby Boomers, Generasi X dan Generasi Y merupakan isu menarik dari tahun ke tahun dalam berbagai studi, di antaranya psikologi, manajemen, dan sumber daya manusia(Padgett, Gossett, Mayer, Chien, \& Turner, 2017)

Tabel berikut merangkum karakter masing - masing generasi dari beberapa studi.

\begin{tabular}{|c|c|c|c|c|}
\hline Deskripsi & $\begin{array}{l}\text { Generasi } \\
\text { Tradisionalis }\end{array}$ & $\begin{array}{l}\text { Generasi Baby } \\
\text { Boomers }\end{array}$ & Generasi X & Generasi Y \\
\hline $\begin{array}{l}\text { Tahun } \\
\text { Kelahiran }\end{array}$ & $\begin{array}{l}1928-1945 \\
\text { (Sprague, } \\
2008)\end{array}$ & $\begin{array}{l}1946-1964 \\
\text { (Sprague, 2008) }\end{array}$ & $\begin{array}{l}1965 \text { - } 1979 \text { (Casey \& } \\
\text { Denton, 2006) 1964 - 1981 } \\
\text { (Schofield \& Honore, 2008) } \\
1965 \text { - } 1979 \text { (Sprague, } \\
\text { 2008) } 1960 \text { - 1978 } \\
\text { (Macleod, 2008) } 1965 \text { - } \\
1980 \text { (Dries, Pepermans \& } \\
\text { De } \\
\text { Kerpel, 2008) } 1962-1979 \\
\text { (Cennamo \& Gardner, 2008) }\end{array}$ & $\begin{array}{l}1980 \text { - } 2000 \text { (Casey \& } \\
\text { Denton, 2006, Sprague, } \\
\text { 2008, Cennamo \& Gardner } \\
2008 \text { ) } \\
1982 \text { - ke atas (Schofield \& } \\
\text { Honore, 2008) } \\
1979 \text { - } 1994 \text { (Macleod, } \\
2008 \text { ) } \\
1981 \text { - } 2001 \text { (Dries, } \\
\text { pepermans \& De Kerpel, } \\
2008 \text { ) }\end{array}$ \\
\hline
\end{tabular}


Philanthropy Journal of Psychology

Vol 2 Nomor 2 (2018), 114-127

ISSN 2580-6076 (Print), ISSN 2580-8532 (Online)

\begin{tabular}{cllll}
\hline Karakter & $\begin{array}{l}\text { Menghormati } \\
\text { otoritas, } \\
\text { menghargai } \\
\text { nilai finansial }\end{array}$ & $\begin{array}{l}\text {-Kurang mempercayai } \\
\text { otoritas dibandingkan } \\
\text { dan }\end{array}$ & $\begin{array}{l}\text { Mengandalkan diri \& afiliasi } \\
\text { kenerasi sebelumnya }\end{array}$ & $\begin{array}{l}\text {-Mendengarkan orangtua, } \\
\text { menghormati otoritas, lebih }\end{array}$ \\
kemapanan & peristiwa Watergate & & suka dibim-bing oleh Baby \\
(Sprague, & komitmen utk dunia & Boomers dari pada rekan \\
2008) & yang lebih baik & seusia, orang tua sebagai \\
& (Sprague, 2008) & panutan (Sprague, 2008) \\
& & -Perkembangan teknologi \\
& & pesat \\
& & - Ambisius, percaya diri, \\
& & optimis, kerja tim (Strauss \\
& & \& Howe dalam Wilson \& \\
Gerber, 2008)
\end{tabular}

Setiap generasi membutuhkan pemimpin dan karakter yang berbeda beda. Khusus untuk menjadi pemimpin untuk generasi milenial harus memiliki karakteristik :

\section{Mampu menjadi teladan yang baik}

Setiap manusia dalam suatu generasi adalah pemimpin yang harus siap untuk memimpin apa dan siapa yang pimpin. Hanya saja posisi atau status turut menentukan sebesar apa tanggungjawab kita sebagai pemimpin. Jika sebagai presiden, maka sudah barang tentu ia memimpin suatu negara yang tanggungjawabnya tentu sangat besar mencakup hal ikhwal satu negara, jika sebagai gubernur, maka ia mempunyai tanggungjawab memimpin masyarakat satu provinsi, begitu juga seseorang sebagai individu maka sudah barang tentu ia bertanggungjawab memimpin dirinya sendiri (Wilbon, 1997).

Ada satu hal penting yang cukup menarik mengenai konsep kepemimpinan untuk masyarakat milenial yakni kepemimpinan itu merupakan suatu karakter dari seorang pemimpin yang mana salah satunya seseorang pemimpin harus menjadi teladan bagi orang lain atau bagi masyarakat yang dipimpinnya. Layaknya posisi seorang ibu dan ayah bagi anak dalam lingkungan keluarga, maka seorang pemimpin juga seolah menjadi orang tua bagi masyarakat yang dipimpinnya, masyarakat milenial tersebut pada akhirnya akan mencontoh apa yang dilakukan oleh pemimpin. Maka sebagai seorang pemimpin untuk era milenial, selain harus mempunyai jiwa kepemimpinan yang baik, mempunyai kapasitas dan kapabilitas dalam memimpin sehingga bisa menciptakan kondisi yang efektif, efisien dan produktif, juga seorang pemimpin milenial harus mampu mempunyai karakter atau atitude yang baik sehingga ia menjadi teladan bagi rakyatnya. Segala tindak tanduk pemimpin akan menjadi penilaian bagi masyarakatnya, baik itu tindakannya sebagai pemimpin suatu lembaga atau 
Philanthropy Journal of Psychology

Vol 2 Nomor 2 (2018), 114-127

ISSN 2580-6076 (Print), ISSN 2580-8532 (Online)

dalam hal tindakan ia sebagai masyarakat biasa termasuk dalam ranah sosialisasi dengan masyarakatnya (Huffman, 2015).

Jika seorang pemimpin sudah mampu menjadi teladan bagi rakyatnya dalam berbagai hal, maka diharapkan bahwa rakyat yang dipimpinnya juga akan mengikuti sikap dari pemimpinnya sehingga rakyat akan lebih simpati terhadap pemimpin. Hal ini bisa berdampak luas, karena selain membangun rakyat yang baik, juga akan meningkatkan efektifitas pembangunan, diharapkan ketika seorang pemimpin menjadi contoh baik bagi rakyatnya, maka masyarakat akan lebih antusias dalam mengikuti intruksi dan ajakan dari pemerintah termasuk dalam melaksanakan setiap program kerja seorang pemimpin yang memang memerlukan partisipasi aktif dari masyarakat itu sendiri(Limbos \& Casteel, 2008).

Ketika dalam suatu negara sudah banyak terjadi hal hal tindakan pemerintah yang kurang baik, seperti korupsi, penyimpangan sosial dan lain sebagainya. Hasilnya selain masyarakat yang tidak mendapatkan contoh yang baik dari pemimpinnya, juga mucul ketidak percayaan dari rakyat kepada pemerintah yang tentunya hal ini sangat merugikan dalam proses pemerintahan di negara tersebut. Maka dari itu sebagai seorang pemimpin, sudah seharusnya kita membangun sikap yang baik agar menjadi teladan bagi siapa nanti yang kita pimpin, sehingga terbangun masyarakat yang baik dan menciptakan efektifitas dalam pembangunan karena diharapkan adanya antusias yang besar dari rakyat milenial terhadap pemimpinya(Wu, Tang, Dong, \& Liu, 2015).

\section{Mempunyai rasa tanggung jawab}

Manusia adalah makhluk sosial yang menjadi pemimpin bagi dirinya sendiri dan menjadi pemimpin bagi orang lain. Menjadi pemimpin berarti menjadi seseorang yang memiliki tanggung jawab lebih dalam hidup. Ada ungkapan dari Warren G. Bennis seorang pelopor studi kepemimpinan kontemporer mengatakan bahwa mitos kepemimpinan yang paling berbahaya adalah "bahwa pemimpin dilahirkan, bahwa ada faktor genetik yang untuk kepemimpinan. Itu hanya omong kosong yang pada kenyataannya kebenarannya adalah sebaliknya. Pemimpin sendiri bukan dari bawaan lahir melainkan diciptakan dan disiapkan (Bell, 2015).

Pemimpin adalah seseorang yang menggunakan kemampuannya, sikapnya, nalurinya, dan ciri-ciri kepribadiannya yang mampu menciptakan suatu keadaan, sehingga orang lain yang dipimpinnya dapat saling bekerja sama untuk mencapai tujuan. Seorang pemimpin 
Philanthropy Journal of Psychology

Vol 2 Nomor 2 (2018), 114-127

ISSN 2580-6076 (Print), ISSN 2580-8532 (Online)

dengan melaksanakan tugas berdasarkan prinsip dasar manajemen, yaitu perencanaan, pengorganisasian, pelaksanaan dan pengendalian sehingga mampu menciptakan keadaan orang lain yang dipimpinnya saling bekerja sama untuk mencapai tujuan. Selain itu pemimpin harus mempunyai kreatifitas yang tinggi (Ali \& Waqar, 2013).

Pemimpin yang ideal salah satunya pemimpin yang bertanggung jawab. Bertanggung jawab berarti berani untuk menanggung efek dari segala keputusan yang timbul akibat tindakan yang telah dilaksanakan. Selain cerdas dan berinisatif, seorang pemimpin yang ideal tentunya perlu memiliki sifat bertanggung jawab. Pengambilan keputusan terhadap cara kerja dan pelaksanaan misi suatu kelompok tentunya diputuskan dengan tidak tergesagesa(Setyaningrum, 2017).

Dalam pengambilan keputusan, pemimpin harus menjadi seorang pendengar yang baik. Bahwa pemimpin pendengar yang baik merupakan seorang pendengar yang baik terlebih ketika orang-orang disekitarmu datang untuk meminta saran dan berbagi. Mereka secara sadar datang kepadamu untuk berbicara karena mereka tahu bahwa, akan mendengarkan dan apa yang mereka katakan akan dihargai. Sebagai pemimpin, tidak langsung memberikan solusi melainkan fokus untuk membimbing dan menasehati agar orang itu sendirilah yang menemukan solusi tersebut dan menjalaninya. Dalam menemukan solusi tersebut harus keluar dari out of the box, dan selalu memiliki pandangan jauh kedepan serta memiliki pengetahuan yang luas, sehingga bisa diandalkan untuk memberikan solusi (S. J. Lambert, 2000).

Maka, pemimpin yang bertanggung jawab adalah pemimpin yang tetap teguh dan mampu berpikir taktis untuk menerima segala resiko yang timbul dari keputusan yang diambil. Pemimpin selalu berjiwa besar, menerima kritik dan selalu mengambil tanggung jawab atas semua keputusan yang ia ambil. Serta tidak pernah mencari kambing hitam atau menyalahkan orang di sekitarnya (Chullen, Dunford, Angermeier, Boss, \& Boss, 2010).

\section{Berani mengambil resiko}

Dalam sebuah diri seseorang terdapat sebuah mental yang ada pada diri masingmasing, dan taukah anda kalau mental adalah sebuah kunci keberhasilan dari individu tersebut, jika pada individu mempunyai mental yang kuat maka presentasi dari tingkat keberhasilannya akan besar, hal ini dikarenakan bahwa mental sangat mempengaruhi seseorang dalam mengambil keputusan sehingga jika seorang individu tersebut mempunyai 
Philanthropy Journal of Psychology

Vol 2 Nomor 2 (2018), 114-127

ISSN 2580-6076 (Print), ISSN 2580-8532 (Online)

mental yang cukup besar maka individu tersebut dapt memutuskan suatu keputusan dengan cepat sehingga dia akan lebih cepat untuk mengetahui apakah keputusannya tersebut adalah hal yang baik atau buruk. disinilah kita mendapatkan pembelajaran dari sebuah keputusan kita sendiri, sehingga kita akan cepat tumbuh menjadi seorang yang dewasa dan mempunyai pengalaman untuk menjadi seorang yang lebih baik, karena jika seorang individu tersebut dalam mengambil keputusan yang lambat maka dia akan lambat tumbuh dewasa dan akan lambat menjadi seorang yang baik karena ketangkasan dalam mengambil keputusan memerlukan kecepatan berfikir dan berani mengambil resiko debagi konsekuensinya (Khan, Salleh, \& Hemdi, 2016).

Konsekuensi apapun yang akan kita dapatkan dari sebuah keputusan, haruslah kita sikapi dengan positif karena hal itu dapat menjadi pemacu kehidupan kita dalam membangun integritas diri dan menyikapi suatu masalah, hal inilah yang dialami oleh para pemimpin bangsa kita yaitu keterlambatan dalam menyikapi masalah sehingga menyebabkan lambatnya negara kita dalam berkembang dikarenakan lambatnya sang pemimpin dalam menyikapi sebuah masalah dan ketidak beraniannya pemimpin kita dalam mengambil resiko karena hal yang terdapat dalam otak para petinggi negara kita hanyalah uang sehingga mengorbankan kedewasaan negara kita sendiri dan berakibatkan pada perekonomian negara(Choi, 2014).

\section{Sense of belonging (merasa ikut memiliki), Sense of participation (merasa ikut serta) dan Sense of responsibility (merasa ikut bertanggung jawab).}

Dalam sebuah perkumpulan tidak akan terlepas dari sosok seorang leaders, mulai dari perkumpulan sederhana sampai oranganisasi besar peran pemimpin sangat vital. Maju mundurnya sebah organisasi sangat tergantung dari seorang leaders. Pemimpin adalah sosok yang sangat berperan dalam menahkodai sebuah organisasi. Tetapi sehebat apapun kepemimpinan seseorang tanpa didukung dengan managemen tim yang bagus itupun akan percuma, jadi kesolidan sebuah organisasi juga sangat penting agar oranganisasi itu bisa terus melaju sesuai dengan cita-citanya. pemimpin mempunyai tanggung jawab memastikan setiap anggotanya bekerja dengan baik, pemimpin juga harus memastikan program-program kerja berjalan. selain itu seorang pemimpin juga harus mempunyai kepekaan sosial yang tinggi, pemimpin tidak bisa bertindak semena-mena menyuruh ini itu, tanpa melihat kondisi lapangan atau anggota. Pemimpin harus tegas tetapi juga harus bijak dalam mengambil setiap keputusan. pemimpin yang tidak kreatif adalah pemimpin yang gagal, karena seharusnya 
Philanthropy Journal of Psychology

Vol 2 Nomor 2 (2018), 114-127

ISSN 2580-6076 (Print), ISSN 2580-8532 (Online)

pemimpin harus memunculkan inovasi-inovasi dalam setiap gagasannya, memunculkan halhal baru dengan gagasan-gagasan yang sepektakuler, beda dengan yang lainnya. pemimpin bukan mereka yang hanya menerima mandat lalu menjalankan tugas kalau seperti ini bukan pemimpin tetapi PLT (Dillard, Hale, \& Segrin, 1994).

Pemimpin harus punya program dan harus berani mengambil setiap keputusan. Pemimpin juga harus bisa menyemai kekompakan, memelihara loyalitas setiap anggota, memastikan anggota loyal padanya. bukan berarti ia seorang yang otoriter, tetapi memang setiap anggota harus berada dalam jalur visi misi seorang pemimpin kalau tidak, maka akan menjadi benalu bagi kepemimpinannya. Bukan pemimpin bila ia lari dari tanggung jawab, maka pemimpin yang baik ia harus bertanggung jawab terhadap semua kegiatan yang menjadi programnya. Pemimpin yang baik, bukanlah ia yang selalu merasa paling benar, tetapi pemimpin yang baik adalah orang yang selalu menerima masukan dari anggota-anggota mempertimbangannya dan mengambil keputusan dengan musyawarah. Selain itu seorang pemimpin ialah motivator, pemimpin harus mampu memberi motivasi kepada anggotaanggotanya, agar mereka menjalankan tugas-tugasnya dengan penuh semangat dan penuh dedikasi dan tanggung jawab. Dan pemimpin yang baik itu ia yang tidak segan memberi pujian penghargaan kepada anggotanya (Shang, Huang, \& Guo, 2010).

\section{Menciptakan kerjasama yang baik di kalangan anggota}

Dalam suatu organisasi atau perusahaan, untuk mencapai tujuan bersama diperlukan suatu kerjasama dari anggota-anggota yang ada di dalamnya. Pentingnya menjalin kerjasama dalam organisasi akan berdampak positif terhadap kinerja yang efektif. Salah satu hal yang mengawali lahirnya kerjasama adalah jalinan komunikasi yang baik. Komunikasi merupakan hal terpenting dalam keberhasilan suatu organisasi atau perusahaan. Jika anggota dalam perusahaan tersebut menjalin komunikasi dengan baik maka perusahaan tersebut mempunyai peluang besar untuk meraih keberhasilan (Lu et al., 2010).

Terbentuknya komunikasi yang mengawali kerjasama tim dalam perusahaan, tidak semudah dilaksanakan. Kesuksesan perusahaan yang didasari kemampuan para anggota untuk bekerja sama ditentukan oleh komunikasi yang baik. Oleh karena itu, setiap perusahaan mempunyai kewajiban untuk mengembangkan komunikasi dari berbagai pihak, baik itu antara pemimpin, anggota, dan masyarakat di sekitar lingkungan kerja agar dapat membantu mewujudkan kerjasama timyang baik (Mangi, n.d.). 
Philanthropy Journal of Psychology

Vol 2 Nomor 2 (2018), 114-127

ISSN 2580-6076 (Print), ISSN 2580-8532 (Online)

Menjadi seorang pemimpin yang baik pada generasi masyarakat milenial saat ini dan kedepan menjadi satu tantangan yang kritis. Banyak pendapat yang mengatakan bahwa kepemimpinan merupakan karakter sejak lahir. Pada zaman ketika pemimpin dilahirkan dari para raja-raja bisa dikatakan demikian karena yang mendapatkan ilmu-ilmu dan pengalaman kepemimpinan hanya ada di lingkungan kerajaan (Carlyle, 2008).

Namun seiring perkembangan zaman, banyak pemimpin muncul akibat tuntutan dan kondisi lingkungan pada saat itu. Pada zaman penjajahan karakter para pemimpin terbentuk dalam perjuangan melawan penjajah. Mereka pejuang yang terbentuk oleh intelektual dan memiliki idealisme yang bisa menghasilkan rumusan ideologi bangsa yang menjadi dasardasar dan pedoman perjalanan dan kehidupan bangsa kita (Huey Yiing \& Zaman Bin Ahmad, 2009).

Namun mencari pemimpin yang tepat untuk masa sekarang dan akan datang menjadi tantangan yang harus dipenuhi untuk bangsa ini. Pemimpin harus bisa beradaptasi dengan perkembangan zaman. Negara-negara maju memiliki pemimpin yang berhasil memanfaatkan perkembangan teknologi yang mengubah pola kehidupan manusia. Selain itu pemimpin juga harus memiliki empati yang tinggi dan komitmen menolong sesama tanpa membedakan suku, agama maupun ras (Mogotsi, Boon, \& Fletcher, 2011).

Pemimpin juga harus memliki sifat berani mengambil keputusan yang terbaik untuk kepentingan rakyat atau golongannya. Yang terpenting dari semua karakter tersebut seorang pemimpin harus memiliki sifat jujur, karena ketidakjujuran bisa merusak sendi-sendi dalam berbangsa dan bernegara. Ketidakjujuran adalah sebuah penyakit yang sangat sulit diobati. Sekali melakukan kebohongan akan menuntut ketidakjujuran-ketidakjujuran berikutnya(Kamani \& Namdari, 2012).

Sebagai bangsa yang besar dan semakin diperhitungkan di kancah internasional, Indonesia memiliki banyak tantangan yang harus diselesaikan. Membangun Indonesia berarti membangun mental rakyatnya sehingga gagasan revolusi mental pun lahir dan dicetuskan pemerintah sebagai gerakan yang masif. Untuk proses perubahan besar itu, kepemimpinan model lama tidak akan cocok lagi dan oleh karena itu harus dikoreksi atau dikembangkan. Dengan generasi muda di Indonesia yang tumbuh begitu pesat, maka gaya kepemimpinan yang muncul pun harus menyesuaikan ritme dan polanya. Generasi milenial yang saat ini memengaruhi banyak hal juga harus dipimpin dengan gaya kepemimpinan milenial (E. G. Lambert, Hogan, Dial, Altheimer, \& Barton-Bellessa, 2012). 
Philanthropy Journal of Psychology

Vol 2 Nomor 2 (2018), 114-127

ISSN 2580-6076 (Print), ISSN 2580-8532 (Online)

Ketika kita membaca berbagai literatur tentang kepemimpinan, istilah kepemimpinan milenial mungkin belum muncul dalam buku-buku teks. Gagasan revolusi mental ini jelas memerlukan penerjemahan lebih lanjut. Tentu saja tak ada definisi yang mutlak untuk pola kepemimpinan milenial yang memang menjadi bagian dari adaptasi perubahan zaman.

Kepemimpinan milenial ini penulis terjemahkan sebagai kepemimpinan masa kini yang menyesuaikan dengan gaya generasi baru yang lahir di era 1980-an. Pola kepemimpinan milenial tidak sama dengan pola kepemimpinan lama dari generasi sebelumnya. Tahun kelahiran 1980-an itu penting karena generasi tersebut saat ini memasuki masa paling produktif. Di usia 30-an tahun, generasi inilah yang menggerakkan dunia kerja, dunia kreativitas, dunia inovasi, dan memengaruhi pasar dan industri global yang ada sekarang sedang menggelinding di lapangan kompetisi dunia kerja, dunia kreativitas, dunia inovasi. Karena itu pula, generasi yang lahir di era 1980-an ke atas biasa disebut generasi milenial. Dengan merujuk pada generasi itu, gaya kepemimpinan yang dibangun pun perlu beradaptasi dengan pola pikir dan gaya hidup mereka. Dan ketika kepemimpinan yang ada hendak melakukan revolusi mental pada bangsa, generasi inilah yang menjadi target penting untuk disasar (Myrsiades, 1987).

Beberapa karakter generasi milenial ini adalah, pertama, kemampuan mereka mengakses teknologi informasi yang lebih baik dari generasi sebelumnya. Media sosial menjadi bagian kehidupan mereka sehari-hari. Internet pun menjadi sumber informasi dan pengetahuan bagi mereka. Apa pun kebutuhan informasi yang mereka perlukan, sebagian besar mereka peroleh dari internet dan media sosial.

Kedua, generasi milenial lebih memiliki keberanian dalam berinovasi. Mereka lebih termotivasi menciptakan startup atau merintis usaha dan bisnis baru. Karena itu merupakan bagian dari tantangan yang membuat adrenalin mereka mengalir.

Ketiga, generasi milenial lebih menyukai independensi dan kemandirian. Independensi ini merupakan kebutuhan yang lahir dari gaya hidup yang ingin lebih bebas dan mandiri dalam melakukan sesuatu. Keempat, generasi milenial lebih menyukai sesuatu yang instan. Mungkin ciri ini bisa dipersepsikan secara positif atau negatif. Positifnya, generasi ini menyukai sesuatu yang praktis dan simpel. Negatifnya, generasi ini mungkin memiliki daya tahan yang lebih rendah terhadap tekanan dan stres karena terbiasa melakukan sesuatu dengan cepat dan instan sehingga kurang sabar jika hasil yang diperoleh tidak muncul seketika. 
Philanthropy Journal of Psychology

Vol 2 Nomor 2 (2018), 114-127

ISSN 2580-6076 (Print), ISSN 2580-8532 (Online)

Dengan memahami karakter generasi milenial ini, kepemimpinan yang muncul pun perlu menjadi bagian dari figur yang cocok dengan mereka. Penerjemahan tentang kepemimpinan milenial ini pun fleksibel dan belum ada definisi mutlak dari para pakar kepemimpinan (Shanker, 2016).

Meski demikian, beberapa yang dapat ditekankan dalam pola kepemimpinan ini antara lain, pertama, kepemimpinan milenial perlu memahami dan memakai pola komunikasi generasi milenial yang dipimpinnya. Misalnya pemimpin milenial tidak segan menggunakan media sosial seperti Twitter, Facebook, Instagram, YouTube, MeTube, dan saluran komunikasi terbaru yang memang menjadi arus utama dalam kehidupan generasi baru itu.

Kedua, kepemimpinan milenial perlu mendorong inovasi, kreativitas, dan jiwa entrepreneurship generasi baru itu. Semua saluran inovasi, kreativitas dan entrepreneurship harus dirancang dengan baik dan kongkrit. Jangan hanya berisi wacana saja, tapi bangunlah proses yang benar-benar dapat dinikmati oleh generasi milenial ini mengembangkan dirinya. Misalnya pemimpin milenial perlu membangun pusat-pusat kreativitas di setiap kota. Bangunlah sebanyak mungkin workshop dengan peralatan dan teknologi terbaru. Biarkan gagasan dan ide generasi milenial itu tersalurkan. Di tiap workshop itu bisa diberi misalnya printer tiga dimensi (3D), komputer grafis tercanggih, jaringan internet gratis berkecepatan tinggi, peralatan kerajinan lengkap, dan sebagainya. Semua itu harus bisa diakses generasi milenial secara gratis atau jika memang harus membayar pun harus terjangkau. Ketiga, kepemimpinan milenial perlu mendukung kemandirian dan jiwa entrepreneurship generasi milenial. Membangun bangsa harus memiliki fondasi utama yakni kemandirian dan entrepreneurship(Lieberman, 2006).

Harus diakui, kesalahan pola pendidikan pada generasi lama ialah kemandirian dan jiwa entrepreneurship mereka tidak dibangun secara kokoh sejak dini. Pendidikan kemandirian dan entrepreneurship ini penting bagi masa depan bangsa dan negara untuk bersaing dengan bangsa-bangsa lain yang selama ini mendominasi berbagai bidang dan industri. Kepemimpinan milenial harus menyadari poin penting ini dalam membangun mental generasi baru(Yoon, Jang, \& Lee, 2016).

Dengan beberapa poin di atas, tentu secara langsung telah menjadi bagian dari revolusi mental yang ingin dibangun pemerintah sekarang. Revolusi mental pun sebagai konsep dan ide masih sangat fleksibel untuk disempurnakan. Ketika revolusi mental ini 
Philanthropy Journal of Psychology

Vol 2 Nomor 2 (2018), 114-127

ISSN 2580-6076 (Print), ISSN 2580-8532 (Online)

dibangun pada tataran pemimpin dan rakyatnya, tentu bangsa akan mengalami kemajuan pesat di tengah perkembangan zaman yang sangat cepat. Revolusi mental tak hanya diperlukan untuk rakyatnya tapi juga untuk para pemimpinnya yang sekarang mengemban tugas dan tanggung jawab untuk memajukan bangsa ini sejahtera. Dengan menggabungkan antara pola kepemimpinan milenial dan revolusi mental, konsep baru ini diharapkan memiliki daya dorong yang kuat pada upaya memajukan bangsa. Ketika konsep ini benar-benar diterapkan di berbagai wilayah di Indonesia maka hasil konkretnya dapat terlihat dari munculnya generasi milenial yang tangguh, mandiri, inovatif, dan kreatif. Merekalah yang akan membuat bangsa ini disegani di kancah internasional(Altuntas \& Baykal, 2010).

\section{Simpulan}

Diprediksi, pada tahun 2030 diperkirakan sebesar 70 persen pemimpin masa depan di Indonesia berasal dari generasi millenial yang berada pada usia produktif. Generasi inilah yang memegang kendali atas perekonomian Indonesia di masa datang dan diharapkan mampu untuk membawa bangsa ini menuju ke arah pembangunan yang lebih maju dan dinamis. Generasi milenial sebagai target utama dalam berbagai program pemberdayaan pendidikan yang selalu nanamkan karakteristik unik milenial yang dirangkum dalam istilah 3C, yaitu critical (kritis), creative (kreatif), dan confidence (percaya diri).

\section{Daftar Pustaka}

Ali, U., \& Waqar, S. (2013). Teachers' Organizational Citizenship Behavior Working Under Different Leadership Styles. Pakistan Journal of Psychological Research, 28(2), 297-316.

Altuntas, S., \& Baykal, U. (2010). Relationship Between Nurses' Organizational Trust Levels And Their Organizational Citizenship Behaviors. Journal of Nursing Scholarship, 42(2), 186-194. https://doi.org/10.1111/j.1547-5069.2010.01347.x

Bell, E. E. (2015). Understanding African American Males ' Schooling Experiences: A Qualitative Inquiry Understanding African American Males ' Schooling Experiences: A, 20(8), 1260-1269.

Bosscher, I. C. (2013). My How Things Have Changed! Strategic Organization Development and the Transformation of Human Resource Management My How Things Have Changed ! Strategic Organization Development, 18(20), 1-5.

Brander, R. A., Patterson, M., \& Chan, Y. E. (2012). The Qualitative Report Fostering Change in Organizational Culture Using a Critical Ethnographic Approach Fostering Change in Organizational Culture Using a Critical Ethnographic Approach. The Qualitative Report, 17(45), 1-27. Retrieved from http://nsuworks.nova.edu/tqr\%5Cn http://nsuworks.nova.edu/tqr/vol17/iss45/2

Carlyle, E. (2008). Organizational Cultural Design Factors Leading to Positive Behavior Changes Among Employees. https://doi.org/UMI : 3257958 
Philanthropy Journal of Psychology

Vol 2 Nomor 2 (2018), 114-127

ISSN 2580-6076 (Print), ISSN 2580-8532 (Online)

Choi, S.-Y. (2014). The Effects of Leadership on Social Workers' Organizational Commitment: Focussing on Ethical Leadership, Organizational Trust, and Supervisor Trust. Information, 17(10(A)), 4771-4778.

Chullen, C. L., Dunford, B. B., Angermeier, I., Boss, R. W., \& Boss, A. D. (2010). Minimizing Deviant Behavior In Healthcare Organizations: The Affects Of Supportive Leadership And Job Design. Journal of Healthcare Management, 55(240), 381-397.

Cullen, K. W., Baranowski, T., Baranowski, J., Hebert, D., DeMoor, C., Hearn, M. D., \& Resnicow, K. (1999). Influence of School Organizational Characteristics on the Outcomes of a School Health Promotion Program. Journal of School Health, 69(9), 376-380. https://doi.org/10.1111/j.1746-1561.1999.tb06433.x

Dillard, J. P., Hale, J. L., \& Segrin, C. (1994). Close Relationships in Task Environments: Perceptions of Relational Types, Illicitness, and Power. Management Communication Quarterly, 7(3), 227-255. https://doi.org/10.1177/0893318994007003001

Egbert, M. D., \& Pérez-Mercader, J. (2016). Adapting to Adaptations: Behavioural Strategies that are Robust to Mutations and Other Organisational-Transformations. Scientific Reports, 6(January), 1-10. https://doi.org/10.1038/srep18963

Erkutlu, H. (2011). The Moderating Role Of Organizational Culture In The Relationship Between Organizational Justice And Organizational Citizenship Behaviors. Leadership \& $\begin{array}{llll}\text { Organization Development Journal, 532-554. } & \text { 32(6), }\end{array}$ https://doi.org/10.1108/01437731111161058

Huey Yiing, L., \& Zaman Bin Ahmad, K. (2009). The Moderating Effects Of Organizational Culture On The Relationships Between Leadership Behaviour And Organizational Commitment And Between Organizational Commitment And Job Satisfaction And Performance. Leadership \& Organization Development Journal, 30(1), 53-86. https://doi.org/10.1108/01437730910927106

Huffman, J. B. (2015). Organizational Behavior: Perceptions Analysis Of Micro And Macro Organizational Behavior In An Organizational Setting Joshua T . Delich , B . A ., Me . D . Dissertation Prepared For The Degree Of Doctor Of Philosophy December 2015 Approved : Don Powell ,.

Kamani, S. M. H., \& Namdari, K. (2012). A Study Of The Relationship Between Organizational Justice And Support And Organizational Citizenship Behavior. International Journal of Arts and Sciences, 5(6), 355-368.

Khan, M. L., Salleh, R., \& Hemdi, M. A. B. (2016). Effect Of Protean Career Attitudes On Organizational Commitment Of Employees With Moderating Role Of Organizational Career Management. International Review of Management and Marketing, 6(4), 155-160. Retrieved from https://www.scopus.com/inward/record.uri?eid=2-s2.084969913395\&partnerID=40\&md5=8a269a1e5ec72ebfb9c968ea7594626d

Koçak, S., \& Burgaz, B. (2017). The Role of Leader Empowering Behaviours in Psychological Contract at High Schools. TeEğitim VBilim, 42(191), 351-370. https://doi.org/10.15390/EB.2017.7101

Lambert, E. G., Hogan, N. L., Dial, K. C., Altheimer, I., \& Barton-Bellessa, S. M. (2012). Examining The Effects Of Stressors On Organizational Citizenship Behaviors Among Private Correctional Staff: A Preliminary Study. Security Journal, 25(2), 152-172. https://doi.org/10.1057/sj.2011.16

Lambert, S. J. (2000). Added Benefits : the Link Between Work-Life Binefits and Organizational Citizenship Behavior. Academy of Management Journal, 43(5), 801-816. https://doi.org/10.2307/1556411

Lieberman, E. A. (2006). What' S Fair Is Fair , Or Is It? The Effects Of Merit-Related 
Managerial Behaviors And Organizational Policies On Organizational Justice Perceptions By Eric A . Lieberman A Dissertation Submitted To The Graduate Faculty In Psychology In Partial Fulfillm.

Limbos, M. A. P., \& Casteel, C. (2008). Schools And Neighborhoods: Organizational And Environmental Factors Associated With Crime In Secondary Schools. Journal of School Health, 78(10), 539-544. https://doi.org/10.1111/j.1746-1561.2008.00341.x

Lu, Y., Bugenhagen, M. J., Ph, D., Carvan, M. K., Ed, D., Reed, J. G., \& Ph, D. (2010). The Relationship Between Leaders ' Behaviors \& Organizational Learning Actions By A Dissertation Submitted In Partial Fulfillment Of The Requirements For The Degree of Doctor Of Philosophy Specialization : Leadership Studies Under The Supervision Of Fond, (August).

Mangi, A. A. (n.d.). Significance of Power and Politics : Its Influence on Organizational Behavior Towards Efficacy, 41(1968), 221-229.

Mogotsi, I. C., Boon, J. A., \& Fletcher, L. (2011). Modelling The Relationships Between Knowledge Sharing, Organisational Citizenship, Job Satisfaction And Organisational Commitment Among School Teachers In Botswana. African Journal of Library Archives $\begin{array}{lll}\text { and Information } & \text { Science, 21(1), }\end{array}$ https://doi.org/10.1017/CB09781107415324.004

Myrsiades, L. S. (1987). Corporate Stories as Cultural Communications in the Organizational Setting. Management Communication Quarterly, 1(1), 84-120. https://doi.org/10.1177/0893318987001001005

Padgett, J., Gossett, K., Mayer, R., Chien, W.-W., \& Turner, F. (2017). Improving Patient Safety through High Reliability Organizations. Qualitative Report, 22(2), 410-425.

Setyaningrum, R. P. (2017). Relationship Between Servant Leadership In Organizational Culture, Organizational Commitment, Organizational Citizenship Behaviour And Customer Satisfaction. European Research Studies Journal, 20(3), 554-569. Retrieved from https://www.scopus.com/inward/record.uri?eid=2-s2.085028028298\&partnerID=40\&md5=3cb8423750e59ad03660ad8bb0fbf300

Shang, H., Huang, P., \& Guo, Y. (2010). Managerial cognition: the sources of sustainable competitive advantage in hypercompetition. Nankai Business Review International, 1(4), 444-459. https://doi.org/10.1108/20408741011082589

Shanker, M. (2016). Organizational Citizenship Behavior and Organizational, 11(2), 397-408.

Somech, Anit: Drach-Zahavy, A. (2004). Exploring Organizational Citizenship Behaviour From An Organizational. Journal of Occupational and Organizational Psychology, 77, 281-298.

Wilbon, A. (1997). Organizational and Developmental Dynamics of Project Review Teams in Technology Environmen. The Qualitative Report, 3(3), 1-20. Retrieved from http://nsuworks.nova.edu/tqr/vol3/iss3/3\%5Cnhttp://nsuworks.nova.edu/tqr/vol3/is s3/3/?utm_source=nsuworks.nova.edu $\% 2$ Ftqr\%2Fvol3\%2Fiss3\%2F3\&utm_medium=P DF\&utm_campaign=PDFCoverPages

Wu, W., Tang, F., Dong, X., \& Liu, C. (2015). Different Identifications Cause Different Types Of Voice: A Role Identity Approach To The Relations Between Organizational Socialization And Voice. Asia Pacific Journal of Management, 32(1), 251-287. https://doi.org/10.1007/s10490-014-9384-x

Yoon, D., Jang, J., \& Lee, J. (Jay). (2016). Environmental management strategy and organizational citizenship behaviors in the hotel industry. International Journal of Contemporary Hospitality Management, 28(8), 1577-1597. https://doi.org/10.1108/IJCHM-10-2014-0498 